\title{
Clinical Profile of Ectopic Pregnancy at a Tertiary Care Centre in Eastern Nepal- A Retrospective Study
}

\author{
Das $A^{* 1}$, Chhetry $M^{1}$, Shrestha $R^{1}$, Rajbhandari $S^{1}$, Sitaula $S^{1}$, Hada $A^{1}$, \\ Shrestha $\mathbf{P}^{2}$
}

${ }^{1}$ Department of Obstetrics and Gynaecology, B.P. Koirala Institute of Health Sciences, Dharan, Nepal. ${ }^{2}$ Department of Obstetrics and Gynaecology, Institute of Medicine, Tribhuvan University Teaching Hospital, Kathmandu Nepal'2.

\begin{abstract}
Introduction: Ectopic pregnancy is a common life-threatening gynaecological surgical emergency. It's incidence is rising globally. It remains a major cause of morbidity and mortality in early pregnancy. The present study is aimed to determine the incidence, risk factors, clinical presentation, diagnosis, management and post-operative outcome of ectopic pregnancies in a tertiary care teaching hospital. Methods: The study was a retrospective study carried out in the Department of Obstetrics and Gynaecology, B.P Koirala Institute of Health Sciences, Dharan, Nepal. Data were retrieved from the medical record section, from the case sheets of gynae admission registers and operative notes in the study duration of one year (January 2019-December 2019). The gynaecological admissions and records of the total births within the period of study were also used in the analysis. Results: During this study period, the incidence of ectopic pregnancy was $0.95 \%$ of total births and $7.46 \%$ of the total gynaecological admissions. The peak age group of incidence was age of 26-30 years. Use of contraception and history of abortion were the main risk factors with contributions of $27.82 \%$ each respectively. Abdominal pain $(86.95 \%)$, amenorrhoea $(81.73 \%)$, vaginal bleeding $(54.78 \%)$ were the most frequent presenting complaints. Ampulla (58.26\%) followed by cornua (8.69\%) were the commonest sites of ectopic implantation. Ovarian pregnancies contributed to only $5.21 \%$. A total of $69.56 \%$ patients presented with ruptured ectopic pregnancy but only $14.78 \%$ had hemodynamic instability. In majority of patients salpingectomy (61.73\%) was done followed by salpingo-oophorectomy (8.69\%). Only $11.30 \%$ received methotrexate in line of medical management and $59.13 \%$ required blood transfusion. There was no maternal mortality. Conclusions: Early diagnosis, timely referral, improved access to health care facility and aggressive management would help to reduce the maternal morbidity and mortality associated with ectopic pregnancy.
\end{abstract}

Keywords: Blood transfusion, ectopic pregnancy, risk factors, salpingectomy.

\section{INTRODUCTION}

The word ectopic pregnancy is derived from the Greek word "ektopos", which means "out of place" (1). It is a common life-threatening gynaecological surgical emergency. It is defined as implantation of the blastocyst anywhere other than in the endometrial cavity, including the fallopian tubes, cervix, ovary, cornual region of uterus and the abdominal cavity. As the abnormally implanted gestation grows and gets its blood supply from the site of abnormal implantation, there is increased chances of organ rupture (2). It is one of the major cause of maternal morbidity and mortality in early trimester and responsible for $80 \%$ of maternal deaths that occur in early pregnancy (3).

Clinical manifestations are diverse. The classic triad of signs and symptoms of Ectopic pregnancy (present in less than $50 \%$ of patients) includes history of a missed menstrual period followed by abnormal vaginal bleeding,

*Address of Correspondence: Dr. Anamika Das, Assistant Professor, Department of Obstetrics and Gynaecology, B.P. Koirala Institute of Health Sciences, Dharan, Nepal.

Email address: dranamikadas123@gmail.com

(Received 07 August 2020; revised 17 August 2020; accepted 07 September 2020) 
abdominal or pelvic pain, and a tender adnexal mass (4). In spite of the comparatively high incidence of ectopic pregnancy, early detection can be difficult. Most of the time ectopic pregnancy can go unidentified at the initial medical evaluation. Usually delayed diagnosis causes serious adverse outcomes in ectopic pregnancies (5).

The chance of recurrence is $7-15 \%$ and there is only $40-60 \%$ chance of conception after surgery (6). The management approach of ectopic pregnancy in our setting is peculiar because rather than early diagnosis and conservative approach in management, we are challenged by late presentations, poor diagnostic tools, limited capacity to handle emergencies with rupture in more than $80 \%$ of cases (7). As a result there is increased maternal morbidity and mortality and reproductive failure (8).

Hence, the utility of prompt diagnosis and accurate treatment is important. So, identifying the incidence, risk factors, clinical presentation, the various treatment modalities and the cause of mortality in those patients might help to improve areas in terms of referral system, patient management protocol, use of multidisciplinary approach and follow up. Conducting an audit in ectopic pregnancy might help in the reduction of number of deaths in future and also provide a learning opportunity from different case scenario by managing preventable cause of death.

\section{AIMS AND OBJECTIVE OF THE STUDY}

The study was conducted to analyse the incidence, the risk factors, the common presentation, the treatment modalities and the management outcome with a view to suggest interventions that would decrease the incidence.

\section{MATERIALS AND METHODS}

This study was conducted in the Department of Obstetrics and Gynaecology, B. P. Koirala Institute of Health Sciences, Dharan, Nepal after obtaining ethical clearance from the Institutional Research Committee (IRC). This was a hospital based retrospective study conducted for a period of one year (January 2019 -December 2019). All patients diagnosed and treated for ectopic pregnancy in the hospital were included in the study. Patients with inadequate data and those patients who refused treatment at this centre were excluded from the study. The case sheets of the patients were traced through the operation theatre registers and the Gynae admission registers. Details of demographic characteristics, risk factors, clinical presentation, operative findings and outcome of treatment given for the ectopic pregnancy as well as associated morbidity and mortality were obtained. Purposive sampling was done. According to Poonam et al., the incidence of Ectopic pregnancy was $2.92 \%$ (9). Considering $2 \%$ as the prevalence of Ectopic Pregnancy, 95\% Confidence interval, $80 \%$ power; the final corrected sample size was 115 . Data collected in the proforma was entered in Microsoft Excel 2013 and was transferred to SPSS version 23.0; SPSS, Chicago, IL, USA. Detailed analysis was done using descriptive statistics and presented as percentages in tables.

\section{RESULTS}

The total number of deliveries during the study period was 12096 and the total gynecologic admissions were 1540.0ne hundred nineteen patients were admitted with the diagnosis of Ectopic pregnancy, of whom data of 115 (96.63\%) patients were retrieved and used for further data analysis, based on which the prevalence of ectopic pregnancy in B P Koirala Institute of Health Sciences is estimated to be 10 in every 1000 pregnancies and $7.46 \%$ of the total gynecological admissions. The incidence of ectopic pregnancy is slightly raised from 9.3 per 1000 deliveries to 10 per 1000 deliveries over the past 15 years in the institute. The incidence of ectopic pregnancy was $0.95 \%$ in our study.

\section{Age distribution}

One third $(\mathrm{N}=39 ; 33.91 \%)$ of the patients belonged to the age group 26-30 years. Lesser incidence $(\mathrm{N}=13 ; 11.30 \%)$ was found in elderly women those who were 36 years and above (Table 1).

\section{Gravidity}

Gravida status ranged from primigravida to fourth gravida and above. Majority of patients patients were gravida two and above $(\mathrm{N}=90$; 78.26\%) (Table 2). 
Table 1: Distribution of patients with age $(\mathrm{N}=115)$

\begin{tabular}{|c|c|c|}
\hline Age(years) & $\begin{array}{c}\text { Number of cases } \\
(\mathrm{N})\end{array}$ & Percentage (\%) \\
\hline $20-25$ & 32 & 27.82 \\
$26-30$ & 39 & 33.91 \\
$31-35$ & 31 & 26.95 \\
$\geq 36$ & 13 & 11.30 \\
\hline Total & 115 & 100 \\
\hline
\end{tabular}

Table 2: Distribution of patients with gravidity $(\mathrm{N}=115)$

\begin{tabular}{|c|c|c|}
\hline Gravida & $\begin{array}{c}\text { Number of cases } \\
(\mathrm{N})\end{array}$ & Percentage (\%) \\
\hline 1 & 25 & 21.73 \\
2 & 30 & 26.086 \\
3 & 32 & 27.82 \\
$\geq 4$ & 28 & 24.34 \\
\hline Total & 115 & 100 \\
\hline
\end{tabular}

\section{Marital status}

Majority $(\mathrm{N}=111 ; 96.52 \%)$ of patients were married. Four patients, $(\mathrm{N}=4 ; 3.47 \%)$ were unmarried (Table 3).

\section{Clinical presentation}

Most of the patients presented with more than one symptoms. But the most common amongst those was abdominal pain as expected. It was present in around ( $\mathrm{N}=100 ; 86.95 \%)$ of the cases. Amenorrhea was present in 94 patients.. More than fifty $50 \%$ of patients $(\mathrm{N}=100,54.78 \%)$ had abdominal tenderness whereas $17.39 \%$ presented with abdominal distension either alone or in combination with other symptoms. In $40 \%$ of the cases, cervical motion tenderness could be elicited. Regarding the duration of ectopic, 21(18.26\%) patients did not miss their periods (Table 4).

\section{Risk factors}

Use of contraception and history of abortion constituted the major risk factors (27.82\%). Spontaneous abortion exceeded the number of induced abortions. 25 patients i.e. $21.73 \%$ had history of previous abdominopelvic surgery .

Majority of patients i.e. $72.17 \%$, were not using any contraception. Three patients gave history of tubal ligation. In this study, two patients, $(1.73 \%)$ had primary infertility whereas $(6.95$ $\%)$ i.e. eight patients had secondary subfertility (Table 5).

Table 3: Distribution of patients according to marital status $(\mathrm{N}=115)$

\begin{tabular}{|c|c|c|}
\hline Marrital status & $\begin{array}{c}\text { Number of cases } \\
(\mathrm{N})\end{array}$ & Percentage (\%) \\
\hline Unmarried & 4 & 3.47 \\
Married & 111 & 96.52 \\
\hline Total & 115 & 100 \\
\hline
\end{tabular}

Table 4: Distribution of patients according to clinical presentation 


\begin{tabular}{|c|c|c|}
\hline & $\begin{array}{c}\text { Number of cases } \\
(\mathrm{N})\end{array}$ & Percentage (\%) \\
\hline Presenting symptoms and sign & 94 & 81.73 \\
Amenorrhea & 21 & 18.26 \\
Periods not missed & 100 & 86.95 \\
Abdominal Pain & 63 & 54.78 \\
Vaginal Bleeding & 15 & 13.04 \\
Vomiting & 10 & 8.69 \\
Syncopal Attacks & 17 & 14.78 \\
Shock & 20 & 17.39 \\
Abdominal distension & 63 & 54.78 \\
Abdominal Tenderness & 48 & 41.73 \\
Adnexal Tenderness & 46 & 40 \\
Cervical motion Tenderness & & \\
\hline
\end{tabular}

Table 5: Distribution of patients according to risk factors

\begin{tabular}{|c|c|c|}
\hline Risk factors & $\begin{array}{c}\text { Number of patients } \\
(\mathrm{N})\end{array}$ & Percentage (\%) \\
\hline Abortion & 32 & 27.82 \\
Spontaneous & 19 & 16.52 \\
Induced & 13 & 11.30 \\
Previous surgery & 25 & 21.73 \\
Bilateral tubal ligation & 2 & 1.73 \\
Appendicectomy & 2 & 1.73 \\
Cesarean section & 15 & 13.04 \\
Previous ectopic & 4 & 3.47 \\
Other abdomino pelvic surgery & 2 & 1.73 \\
Contraception & 32 & 27.82 \\
IUCD & 4 & 3.47 \\
\hline
\end{tabular}




\begin{tabular}{|c|c|c|}
\hline Depo provera & 3 & 2.60 \\
OCP & 15 & 13.04 \\
Barrier & 10 & 8.69 \\
No contraception & 83 & 72.17 \\
Infertility & 10 & 8.69 \\
Primary & 2 & 1.73 \\
Secondary & 8 & 6.95 \\
History of & 4 & 3.47 \\
Tuberculosis & 20 & 17.39 \\
Pelvic inflammatory disease & & \\
\hline
\end{tabular}

Type of ectopic pregnancy

Majority $(\mathrm{N}=80,69.56 \%)$ of patients had ruptured ectopic pregnancy at the time of admission. Unruptured ectopic pregnancy was seen in only $(\mathrm{N}=14,12.17 \%)$ patients. Tubal abortion was present in $18.26 \%$ patients (Table 6).

\section{Site of ectopic pregnancy}

In majority $(\mathrm{N}=85,73.91 \%)$ of patients, the ectopic pregnancy was in fallopian tube. Of these, in about five patients (4.34\%) the exact location could not be made out in ultrasonography and laparotomy both due to extensive tubular damage. In 67 (58.2\%) patients ectopic gestation was located in ampullary part of fallopian tube, followed by isthmus and infundibulum part in nine (7.82\%) patients each. Ovarian ectopic was seen in six (5.21\%) patients Five patients had heterotopic pregnancy. Rudimentary horn rupture was detected intaoperatively in four patients who had presented in a state of shock at the time of admission (Table7).

Table 6: Distribution of patients according to Type of ectopic pregnancy

\begin{tabular}{|c|c|c|}
\hline Type of ectopic pregnancy. & $\begin{array}{c}\text { Number of patients } \\
(\mathrm{N})\end{array}$ & Percentage (\%) \\
\hline Ruptured & 80 & 69.56 \\
Unruptured & 14 & 12.17 \\
Tubal abortion & 21 & 18.26 \\
\hline Total & 115 & 100 \\
\hline
\end{tabular}

Table 7: Distribution of patients according to site of ectopic pregnancy 


\begin{tabular}{|c|c|c|}
\hline Site of ectopic pregnancy & $\begin{array}{c}\text { Number of patients } \\
(\mathrm{N})\end{array}$ & Percentage (\%) \\
\hline Fallopian Tube & 85 & 73.91 \\
Ampulla & 67 & 58.26 \\
Isthmus & 9 & 7.82 \\
Infundibulum & 9 & 7.82 \\
Cornua & 10 & 8.69 \\
Ovarian & 6 & 5.21 \\
Rudimentary Horn & 4 & 3.47 \\
Heterotopic & 5 & 4.34 \\
Fallopian tube but unspecified & 5 & 4.34 \\
\hline
\end{tabular}

\section{Type of surgery}

Majority of patients (N=102, 88.69\%) were managed by surgical methods. Only $(\mathrm{N}=13$, $11.30 \%$ ) patients were managed by medical method where methotrexate was given (Table 8).

Among the surgical method, laparotomy was done in majority $(\mathrm{N}=91,89.69 \%)$ of the patients. Laparoscopy was done only in $(\mathrm{N}=11,9.56 \%)$ patients. The most common procedure which was done was salpingectomy in $(\mathrm{N}=71,61.73 \%)$ of the patients.. In eight patients cornual rupture reconstruction done. There were five ruptured heterotopic pregnancy for which unilateral salpingectomy with suction and evacuation was done (Table 9).

\section{Post-operative management and complications}

Majority $(\mathrm{N}=68,59.13 \%)$ of patients required blood transfusion. $52.17 \%$ had post-op fever. $22.60 \%$ required MICU (Maternal intensive care unit) admission. 8.69\% patients had hospital stay longer than 10 days. Wound infection and urinary tract infection developed in four patients each respectively .There was 12 patients who developed respiratory tract infection However, there was no maternal mortality (Table 10).

Table 8: Distribution of patients according to management options adopted

\begin{tabular}{|c|c|c|}
\hline Management & $\begin{array}{c}\text { Number of patients } \\
(\mathrm{N})\end{array}$ & Percentage (\%) \\
\hline Surgical & 102 & 88.69 \\
Laparoscopy & 11 & 9.56 \\
Laparotomy & 91 & 79.13 \\
\hline Medical & 13 & 11.30 \\
\hline Methotrexate & 115 & 100 \\
\hline Total & & \\
\hline
\end{tabular}

Table 9: Distribution of patients according to Type of surgery 


\begin{tabular}{|c|c|c|}
\hline Management & $\begin{array}{c}\text { Number of patients } \\
(\mathrm{N})\end{array}$ & Percentage (\%) \\
(Laparotomy and laparoscopy) & 71 & 61.73 \\
Salpingectomy & 10 & 8.69 \\
Salpingo oophorectomy & 0 & 0 \\
Salpingostomy & 10 & 6.95 \\
Corneal Resection & 6 & 5.21 \\
Total unilateral salpingectomy & 5 & 4.34 \\
with opposite tubectomy & & \\
Total unilateral salpingectogmy & 5 & \\
with Suction and Evacuation & & \\
\hline
\end{tabular}

Table 10: Distribution of patients according to post-operative complications

\begin{tabular}{|c|c|c|}
\hline $\begin{array}{c}\text { Post-operative Requirements } \\
\text { and complications }\end{array}$ & $\begin{array}{c}\text { Number of patients } \\
(\mathrm{N})\end{array}$ & Percentage (\%) \\
\hline Blood Transfusion & 68 & 59.13 \\
MICU Admission & 26 & 22.60 \\
Hospital stay >10days & 10 & 8.69 \\
Wound Infection & 4 & 3.47 \\
Fever & 60 & 52.17 \\
Urinary tract infection & 4 & 3.47 \\
Respiratory tract infection & 12 & 10.43 \\
Maternal Mortality & 0 & 0 \\
\hline
\end{tabular}

\section{DISCUSSION}

In the present study, the incidence of ectopic pregnancy was $0.95 \%$. We compared the incidence of ectopic pregnancy in the institute from 2002 to 2004 and found that the incidence is slightly raised over the last 15 years $(9.3$ per 1000 deliveries to 10 per 1000 deliveries). Similarly, in a study done by Jophy and Porwa et al., there was an increasing trend in the incidence of ectopic pregnancies (7.4 per 1000 live births to 15.2 per 1000 live births) $(10,11)$. Shobeiri et al., conducted a study of 872 women with ectopic pregnancy in Iran during 2000 to 2010. They found that the incidence of ectopic pregnancy increased from 1.5 per 1000 pregnancy in 2000 to 4.8 per 1000 pregnancy in 2010 (12).

In the present study, $75 \%$ of women were in the age group of 20-35 years. Similarly many studies reported that majority of women diagnosed with ectopic pregnancy belonged to this age group $(11,13-22)$. This is probably because this age group is the period of highest sexual activity and fertility. In the present study, $75 \%$ of the women were multiparous which was comparable with studies by Bhuria et al. , Rakhi et al., Yadav et al. and Prasanna et al. $(14,21$ 23).

We have observed that amenorrhea was present in majority $(81.73 \%)$ of patients. Pain in abdomen, bleeding per vaginum, and vomiting was presented in $86.95 \%, 54.78 \%$ and $13.04 \%$ patients respectively. $8.69 \%$ patients had one or more fainting episode. This is comparable to the study by AO Igwegbe et al. where majority, $80.6 \%(75 / 93)$ presented with abdominal pain and $35.8 \%(33 / 93)$ presented with vaginal bleeding (24). The studies by Perveen $\mathrm{F}$ et al. , Manthan et al. and Shivkumar HC et al. also found almost similar trends of presenting complaints (25-27). However in the study of Hassan $\mathrm{N}$ et al ., abdominal pain was seen in $70.97 \%$, amenorrhea only in $51.61 \%$ and irregular vaginal bleeding in $25.81 \%$ patients (28). In our study, about $14.78 \%$ patients were brought in the state of shock. This is in contrast to the study of Shaikh BN et al. and Shanti Suri Asuri et al. where $38 \%$ and $40.5 \%$ patients were brought in a state of shock $(25,29)$.

The most identified risk factors in this study were mainly use of contraception and spontaneous abortions followed by previous cesarean section, PID, infertility and Tuberculosis. Use of contraception was the principal etiologic factor in this study. This finding is consistent with the internationally identified risk factors for the overall increase in the incidence of ectopic pregnancy. However many patients were not using any contraception prior to the antecedent conception that resulted in an ectopic pregnancy. A large percentage in this study had one or more induced abortions, which were illegally performed under septic 
conditions. In our study $3.47 \%$ patients had pervious ectopic pregnancy, comparable to the studies of Priyadarshini et al., Shanti Suri Asuri $(25,29)$. Progesterone (Depo provera) users constituted $2.60 \%$ of the patients. This slightly increased risk could be due to the inhibitory effect of progesterone on tubal motility.

We found that majority of patients had tubal ectopic pregnancy as in other studies (30, 31). $58.26 \%$ had ectopic in ampulla, followed by isthmus and infundibulum (7.82\%).Ovarian ectopic was seen in $5.21 \%$ patients. Five (4.34\%) patient had heterotopic pregnancy. Almost similar trend was noticed in Bouyer et al's. 10-year study on 1800 patients, who suggested sites of ectopic pregnancy as ampullary (70\%), isthmic (12\%), ovarian (3.2\%) (32).

In our study majority (69.56\%) patients had a ruptured, while only $12.17 \%$ had an unruptured ectopic pregnancy at the time of admission. The incidence of tubal rupture has been found to vary greatly between various studies from $16 \%, 36 \%(29,30)$.

This shows that majority of cases with ectopic pregnancy present as ruptured ectopic pregnancies. This emphasizes the need for early diagnosis. Women with high risk of ectopic pregnancy must be emphasized to consult the obstetrician as early as possible when they miss the periods.

In the present study, all the patients with ectopic pregnancy were managed surgically. (79.13\%) patients underwent laparotomy and $9.56 \%$ patients had laparoscopic treatment. In most studies, surgery has been the main stay of treatment (33).

Since most of our patients had ruptured tubal pregnancy, they needed an emergency laparotomy as a life saving measures. The most common procedure which was done was salpingectomy (61.73\%). Salpingooophorectomy was done in 8.695\%. Four patients had rudimentary horn rupture. Unilateral salpingectomy with suction and evacuation was done for the ruptured heterotopic pregnancy in $4.34 \%$ patients. In Yadav et al's. study also, the most common surgeries done were total unilateral salpingectomy $\quad(70.58 \%), \quad$ Salpingo oophorectomy $(11.76 \%)$. Similar findings were also noted in different studies (30).

Since the incidence of ruptured ectopic pregnancy was high in our study, $59.13 \%$ of the patients were given one or more units of blood transfusion intra operatively and post operatively. Blood transfusion was required in $43.5 \%-97.3 \%$ of patients in other studies (13, $18,19)$. This variability in requirement for blood transfusion was probably because of the difference in severity of presentation, presence of hemoperitoneum, pre-existing anaemia and availability of blood products.

There was no maternal mortality due to ectopic pregnancy in the present study as in other studies $(11,13-20)$. This may be as a result of prompt and proper management of the patients after reporting to the hospital.

Hence, it is seen clearly that while there is an increase in incidence of ectopic pregnancy, mortality has reduced significantly, which can be because of improved diagnostic and treatment modalities.

\section{LIMITATION}

As the study involved samples selected from BPKIHS, a tertiary care referral centre and the samples were conveniently chosen, it did not reflect the scenario of the entire eastern region. Secondly, selection bias might have occurred if missing data appeared.

\section{CONCLUSION}

The incidence of ectopic pregnancy is rising. Due to late diagnosis and delayed referral the incidence of ruptured ectopic pregnancy is high in developing countries. Since many patients may not have identifiable risk factors, a high index of suspicion is vital for early diagnosis. Women at high risk for ectopic pregnancy must be counselled about the possibility for future ectopic pregnancy. They should be emphasised to report to their doctor as soon as they miss their periods for early diagnosis. Avoiding unnecessary pregnancies, safe sex practices, using barrier contraceptives, prompt treatment of PID/STDs can bring down the incidence of ectopic pregnancies. Early diagnosis, timely referral, aggressive management, improvement of blood bank facilities can reduce the maternal morbidity and mortality associated with ectopic pregnancy.

\section{ACKNOWLEDGEMENTS}

I would like to acknowledge all the faculties of Department of Obstetrics and Gynaecology and the respective residents for their help during the study and special thanks to the head of Department for his moral support.

\section{FUNDING}

No funding sources. 


\section{CONFLICT OF INTEREST}

None.

\section{REFERENCES}

1. Kirk E, Bourne T. Ectopic pregnancy. Obstet Gynaecol Reprod Med 2011 ; 21,(7) : 207-211.

2. Sepilian VP, Ectopic Pregnancy. [Online]. 2009 Aug 2 [cited 2009 Nov 25]; Available from: URL: http://emedicine.medscape.com/article/258768overview

3. Confidential Enquiries into Maternal Deaths. Why mothers die 1997-1999: The fifth report of the Confidential Enquiries into Maternal Deaths in the United Kingdom. No.5. Regent's Park, London: RCOG Press 2001.

4. Pearson J, Rooyen J. Ectopic Pregnancy. In: Bankowski BJ, Hearne AE, Lambrou NC, Fox HE, Wallach EE, editors. John Hopkins manual of obstetrics and gynecology. 3rd ed. Philadelphia: Lippincott Williams \& Wilkins; 2007. p. 303-311.

5. Shobeiri F et al., Epidemiology of Ectopic Pregnancy in Hamadan Province. Zahedan Journal of Research in Medical Sciences 114.4 (2012) ; 46-49.

6. Aboyeji AP, Fawole AA, Ijaija MA. Trends in ectopic pregnancy in Ilorin, Nigeria. Nigerian J Surg Res. $2002 ; 4: 6-11$.

7. Igbarese G O, Ebeigbe P N , Igbekoyi O F, Ajufoh B I . Ectopic pregnancy an 11 year review in a tertiary centre in the Niger Delta. Trop Doct. 2005; 35: 175-7. 8. Udigwe G O, Umeononihu O S, Mbachu II. Ectopic pregnancy: a 5 year review of cases at Nnamdi Azikiwe University Teaching Hospital (NAUTH) Nnewi. Niger Med J. 2010; 51(4):160-163

9. Poonam Y, Uprety D, Banerjee B. Ectopic pregnancy-two years review from BPKIHS, Nepal. Kathmandu University Med J. 2005 ; 3: 365-9.

10. Jophy R, Thomas A, Mhaskar A. Ectopic pregnancy -5 year experience. J Obstet Gynecol Ind. 2002 ; 52:558.

11. Gupta R, Porwal S, Swarnkar M, Sharma N, Maheshwari P. Incidence, trends and risk factors for ectopic pregnancies in a tertiary care hospital of Rajasthan. JPBMS. 2012; 16(07):1-3.

12. Shobeiri F, Tehranian N, Nazari M. Trend of ectopic pregnancy and its main determinants in Hamadan province, Iran (2000-2010). BMC research notes. $2014 ; 7(1): 733$.

13. Gaddagi RA, Chandrashekhar AP. A Clinical Study of Ectopic Pregnancy. J Clin Diagn Res. 2012; 6(5):867-9.

14. Shivakumar HC, Umashankar KM, Ramaraju HE. Analysis of forty cases of ectopic pregnancies in tertiary care hospital in south India. Indian Journal of Basic and Applied Medical Research; 2013; 3(1):235241.

15. Wakankar R, Kedar K. Ectopic Pregnancy- A rising Trend. Int J Sci Stud. 2015; 3(5):18-22.
16. Mufti S, Rather S, Mufti S, Rangrez RA, Wasiqa, Khalida. Ectopic pregnancy: an analysis of 114 cases. JK Practitioner. 2012; 17(4):20-3.

17. Shukla DB, Jagtap SV, Kale PP, Thakkar HN.Study of ectopic pregnancy in a tertiary care centre. Int J Reprod Contracept Obstet Gynecol. 2017; 6:975-9.

18. Yadav ST, Kaur S, Yadav SS. Ectopic pregnancy an obstetric emergency: retrospective study from medical college Ambala, Haryana, India.Int J Reprod Contracept Obstet Gynecol. 2016; 5:2210-4.

19. Bhuria V, Nanda S, Chauhan M, Malhotra V. A retrospective analysis of ectopic pregnancy at a tertiary care centre: one year study. Int J Reprod Contracept Obstet Gynecol. 2016; 5:2224-7.

20. Nair L, Peter N, Rose A. International Journal of Biomedical Research 2015; 6(05):331-3.

21.Rakhi, Mital PL, Hooja N, Agarwal A, Makkar P, Andleeb F. Ectopic pregnancy: a devastating catastrophe. Sch J App Med Sci. 2014; 2(3A):903-7.

22. Prasanna B, Jhansi CB, Swathi K, Shaik MV. A study on risk factors and clinical presentation of ectopic pregnancy in women attending a tertiary care centre. IAIM. 2016; 3(1):90-6.

23. Ragab A, Mesbah Y, El-Bahlol I, Fawzy M, Alsammani MA. Predictors of ectopic pregnancy in nulliparous women: A case-control study. Middle East Fertility Society Journal.2016; 21(1):27-30

24. Stabile I, Grudzinski JG. Ectopic pregnancy; what's new? In Studd J editor. Progress in obstetrics and gynaecology, Edinburgh: Churchill Livinstone; 2000:11:281.

25. Eastman NJ, Hellman L. Williams Obst. 12th edition. New York: Appleton century crafts; 1961:130. 26. Bouyer J, Coste J, Shojaei T, and Pouly J, Fernandez H. Risk factors for ectopic pregnancy: a comprehensive analysis based on a large scale control, population based study in France. Am J Epidemiol. 2003; 157(3):185-94.

27. Comprehensive Gynaecology, 3rd edition. Missouri, St Louis: Mosby; 1997:432

28. DeCherney A, Minkin MJ, Spangler S: Contemporary management of ectopic pregnancy. J Reprod Med. 1981; 26:519.

29. Douglas ES, Singleton HM, Crist T: Surgical management of tubal pregnancy: Effect on subsequent fertility. South Med J. 1969; 62:954

30. Jophy R, Thomas A, Mhaskar A. J Obst and Gyn India. 2002; 52:55-8.

31. Douglas ES, Singleton HM, Crist T: Surgical management of tubal pregnancy: Effect on subsequent fertility. South Med J. 1969; 62:954.

32. Deanna D, Caminiti MD, Kathleen L. Smith. An institutional review of the management of Ectopic pregnancy. J Gynecol Surg. 2006; 22(2):47-56

33. Gupta R, Porwal S, Swarnkar M, Sharma N, Maheshwari P. Incidence, trends and risk factors for ectopic pregnancies in a tertiary care hospital of Rajasthan. JPBMS. 2012; 16(7):1-3. 